International Journal of Child, Youth and Family Studies (2013) 1: 1-4

\title{
INTRODUCTION TO THE SPECIAL ISSUE ON CRIME PREVENTION WITHIN THE ALBERTA CONTEXT
}

\author{
John Winterdyk, Guest Editor
}

This Special Issue of the International Journal of Child, Youth and Family Studies is distinctive on a number of levels. First, not all the articles speak directly to families and/or children, as is the case with virtually all articles that appear in this journal. But they do all speak to the issue of crime prevention that directly and/or indirectly impacts families, children, and the community at large. Second, the articles were all funded by the Mount Royal University Centre for Criminology and Justice Research (CCJR) through a grant that was received from the Ministry of Justice and Attorney General of the Province of Alberta. The CCJR represents the first Centre of its type in Alberta. Third, in addition to being funded solely through the same organization, the articles all represent an effort to bridge theory and practice and speak to the importance of exploring and supporting alternatives to conventional criminal justice response mechanisms.

The CCJR officially opened its doors for business in January of 2010. The purpose of the Centre is to provide independently conducted, evidence-informed research involving qualitative and/or quantitative analysis. The CCJR was also created in an effort to provide faculty and students with research opportunities. The idea of such an approach is to help ensure that community agencies and organizations can and will make decisions and implement policies that are in the best interest of their success and sustainability. In a time when there is an increasing call for evidence-based or evidence-informed policy, the CCJR is in a unique position to offer such a broad-based service.

Throughout the provincial funding period (January 1, 2010 to December 31, 2012), the CCJR supported 16 different projects whose primary focus was on crime reduction and crime prevention initiatives. In addition to funding projects, the Centre continues to undertake independently funded projects as well as to submit proposals for funding.

John Winterdyk, Ph.D. is a professor in the Department of Justice Studies, Mount Royal University, 4825 Mount Royal Gate SW, Calgary Alberta, Canada, T3E 6K6, (403) 440-6992. E-mail: jwinterdyk@mtroyal.ca 
This issue is comprised of ten articles. All the funded projects' principal investigators were invited to submit an article version of their final reports for consideration. Although the final selection may not be reflective of traditional journal articles, the articles represent a solid cross-section of the type of research that is being done in Alberta, which is spearheading a new initiative in crime control and crime prevention in the province. Crime prevention, although a long-established goal, has remained a rather marginal priority across the criminal justice spectrum. However, with burgeoning criminal justice budgets, the potential financial impact of the Omnibus Bill (Bill C-10), general public disillusionment with the criminal justice system, consistently high recidivism rates that seem to remain resistant to all traditional remedies (i.e., stiffer and/or longer sentences, surveillance or monitoring techniques, etc.), the general failure of rehabilitation and deterrent theories, it is ever more imperative that we begin to seriously embrace alternative options.

As noted in Alberta's Crime Prevention Framework (Government of Alberta, 2011), Alberta and a number of its communities have set out clear crime intervention strategies that revolve around crime prevention (i.e., primary, secondary, and tertiary) - that is, initiatives that are proactive rather than reactive in their approach. Furthermore, as reflected in the articles presented in this issue, it is evident that there are no issues that cannot be addressed at some level through primary, secondary, or tertiary crime prevention initiatives.

As related in the Crime Prevention Framework report, "violent crime in Alberta remains higher than the national average” and certain crimes, such as gang-related homicides, have increased in recent years (p. 16). The report further notes that focusing on reaction "to crime is not enough" as we also need to address the "underlying factors that contribute to crime” (p. 17).

The report identifies eight strategic directions (p. 7) that revolve around the need to conduct research with academic partners and research entities that are capable of providing evidence-based advice to government to focus on existing and new program initiatives. Of particular importance is that all evidence-based research be guided by the inclusion of measurable outcomes (i.e., strategic direction \#8) that can be used to monitor the relative progress and success of the crime prevention initiative.

The process model recommended in actualizing the strategic direction is based on a simple but effective and practical model whose core purpose is to create and promote safer communities throughout Alberta. The process follows four basic steps. First is to establish priorities that align with the provincial priorities. The second step involves implementing and financially supporting the programs that have undergone a review process. The third phase involves the evaluation (i.e., the measurement and assessment of progress) in accordance with clearly defined and proscribed outcome indicators such as the Social Return on Investment. The final and fourth phase of the Crime Prevention Framework is the diagnosis, which includes addressing the gaps in programs or services (strategic direction \#4) and contributing to the existing research and knowledge base (strategic direction \#1). And while all the articles have a primary focus on the Province of Alberta, it is readily recognizable that all the issues transcend provincial and national boundaries. 
The first article by Leslie MacRae-Krisa is a literature review that focuses on the unique and understudied issue of how best to assist gang members in exiting gangs. The paper aligns itself with the Alberta Gang Reduction Strategy initiative whose primary focus is on reducing gang-related violence. While there is no one method or strategy that is considered best, the article addresses how important it is to understand the complexity of the gang phenomenon before offering any effective intervention strategies.

The second article, again, is a unique study in that Gillian Stevens and her associates forecast the demographic trends and crime patterns in the Province of Alberta up to the year 2020. Relying on official statistics from Statistics Canada, the authors suggest that crime rates are likely to drop largely because of the aging population. The article also provides estimates for a range of crimes and the projected direction of crime trends over the next few years. The article serves to show the value of forecasting.

Next, Kim Sanderson and her colleagues present a case study on the results of school attendance, developmental assets, and social capital in a First Nations community. Adapting a successful model out of the Search Institute in Minneapolis, Minnesota, the authors found a strong correlation between attendance rates and developmental asset scores. Based on their results, the authors offer some suggestions for strengthening community attachments, which in turn will help to reduce social unrest in such communities.

The fourth article by Hieu Ngo and his associates speaks to a growing issue both within Alberta and across Canada. The issue examined is crime prevention within multicultural societies through the use of 10 focus groups in several locations throughout the province. The study identifies a series of risk and protective factors that help to strengthen community ties and reduce the risk and incidence of crime among ethnocultural members.

Cathy Carter-Snell and Sonya Jakubec undertake a quasi meta-analysis of the literature related to intimate partner violence, a topic relatively unexplored in criminology. The article discusses some of the risk and resiliency factors as they relate to intimate partner violence. The article represents a step forward in helping to not only inform future research but also to develop better intervention and prevention programs for prospective victims.

The sixth article by Gaye Warthe and her colleagues also focuses on a unique topic - that of peer-to-peer dating violence. The authors tested the relative effectiveness of a dating violence prevention program for post-secondary students. Although the program shows promise, the authors discuss some of the limitations of their sampling size and methodology.

Next, Dawne Clark et al. present the results of an important study that addresses healthy child development, using the UpStart Parent Survey to test the viability of the survey as a tool to assist in developing a prevention-focused parenting program. Due to limited funding from the CCJR, this study represents the first phase of a proposed multi-phased project to refine the survey.

The next article by Crystal Hincks and her associates presents the result of an evaluation of a pilot program in Grande Prairie in northern Alberta. The PACT (i.e., Police and Crisis 
International Journal of Child, Youth and Family Studies (2013) 1: 1-4

Team) program was developed to respond to the needs of the rural population in the Peace Country region. In addition to including an SROI (Social Return on Investment) evaluation component, the study points to the value of a comprehensive service program to address the needs of families who are facing personal challenges. The article also speaks to some of the pragmatic issues practitioners confront when engaging in applied research.

The ninth article, by a group of authors headed by Lana Wells, focuses on domestic violence within the Filipino community of Calgary. In response to a growing concern in this community about domestic violence, the study represents an exploratory and informative approach contributing to the development of a province-wide plan to address and prevent domestic violence among the target population. In spite of a small sample size, some preliminary observations are offered.

The tenth and final article by Lorne Bertrand and his colleagues examines the risk and protective factors affecting young offenders from one of four ethnically diverse groups who have committed at least one substantive criminal offence. The results bring into focus some of the conventional misconceptions that tend to exist - that is, while there are no statistically significant differences between the ethnic groups in terms of their risk and protective factors, there are a number of significant differences in terms of other variables. The implications of these differences are discussed.

\section{Reference}

Government of Alberta. (2011). Alberta's crime prevention framework. Edmonton, AB: Author. 